\title{
A Comparative Study of Learning Related Emotions among Male and Female Health Field University Students in Saudi Arabia
}

\author{
Ahmed Khtere ${ }^{1}$ \\ ${ }^{1}$ Fayoum University
}

\begin{tabular}{l} 
ARTICLE INFO \\
\hline Keywords: \\
Learning Related \\
Emotion, Health, \\
University Students, \\
Gender.
\end{tabular}

\begin{abstract}
The present study investigates the level of learning related emotions as well as to looks at the differences between female and male undergraduate health tack students for learning related emotions levels. A self-reported measure of learning related emotions was collected from 120 university students from East Saudi Arabia, which were selected by stratified random sampling. The results indicated that students' having good feelings towards their learning at the university. When comparing students' gender groups, the results also showed insignificant differences between males and females' students on their emotions towards their learning at the university. Finally, the study provided recommendations for further research and educational practices.
\end{abstract}

\section{Introduction}

Recently, there are high expectations for higher education institutions generations to provide all sectors of labour market with quality (Mitsis \& Foley, 2012). However, literature supported that students' success can be influenced by several factors such as academic and non-academic factors. Additionally, learning emotions are for example very influential in achieving success. In other words, emotions guide students learning behaviors and well-being which impact their general learning experience by extension their success (Pekrun, Goetz, \& Perry, 2005; Pekrun, Frenzel, \& Thmoas, 2007). Furthermore, learning emotions are the temporary affective states of individuals when taking part in the daily activities of teaching, learning and assessing that is related to the educational system.

However, despite, the importance of the previous studies and their contributions, there is still a lack in studies dedicated to student's success in terms of learning related outcomes on the life of youth in the world (Putwain, Larkin, \& Sander, 2013; Harmon-Jones, Cindy, Amodio, \& Glabe,,

\footnotetext{
$\square$ Corresponding Author E-Mail Address: ahmed.s.a@ fayoum.edu.eg
} 
2011; Zeidner, 1998), and particularly within the Arab world. In addition, evidence supporting the mean level differences in academic emotions in various domains exists, but it remains unclear, by doing so the research attempts to go beyond what prior studies had focused.

Prior studies have suggested that study domain plays a significant role in students' emotions and that different levels of specific emotions are experienced in different environments (Pekrun, Frenzel, \& Thmoas, 2007) as justified by the fact that subject domain may encapsulate different domain value, content difficulty, self-concept and specific abilities that are concerned with the domain, classroom composition, peer support, and classroom instruction. Evidence points to the fact that the mean level differences in academic emotions are different in different domains. Therefore, this study was conducted to identify the level of learning emotions and to compare differences between male undergraduate students and female undergraduate students in health track at the university for emotions related to their learning.

\section{Literature Review \\ Learning Related Emotions}

On the basis of assumptions found in theories and empirical findings, the learning characteristics are linked to emotions experienced in the classroom. The initial method that sheds some light on this linkage was provided by (Pekrun, Goetz, \& Perry, 2005). Based on their proposed theory, discrete learning related emotions can be divided by valence, object-focus, and activation. Valence is the difference between positive and negative emotions while object focus relates to whether or not such learning-related emotion is felt in conjunction with a study activity or an achieved academic goal. It can be retrospective, such as pride, and it is felt after a learning episode. Finally, activation is described as the level of physiological arousal involved in such emotion. Hence, academic emotion may be described as the temporary affective states experienced by students during their engagement in daily activities of teaching, learning, and the assessment. It can be felt and gauged in conjunction with classroom teaching, learning or testing. This makes academic emotions stand out from the other affective types such as mood, which lacks a specific referent and is described as less situation-specific, and generally not as intense or long-lasting compared to emotions in general (Linnenbrink, 2007; Harmon-Jones, Cindy, Amodio, \& Glabe, 2011).

\section{Methodology}

This research was a cross-sectional comparative study of female and female health track students at Imam Abdulrahman Bin Faisal University IAU. The study used the quantitative survey method to looks into the case being studied and provides an accurate description of what the researcher observes (Babbie \& Mouton, 2010). The sample for this study consisted of a group of students who enrolled in the health track at the university. The sample recruited 120 undergraduate students from preparatory year deanship (69 male and 51 female students), selected with the help of stratified sampling method from the Health track in preparatory year Deanship at IAU. Participants were required to answer the questionnaire in order to collect information related to study variable. The study collected informed agreement from the participants prior to the administration of the questionnaire. 
The researcher collected informed agreement from the participants prior to the administration of the questionnaire. A self-report questionnaire was employed in the study for the data collection. The questionnaire categorized two sections; background of the respondents, and the learning related emotions. The learning related emotions adapted version (Pekrun, Goetz, \& Perry, 2005) was administrated to collect information about students' emotions towards learning. The measurement is an internationally validated self-report instrument including three scales which are students emotions with class-related emotions items (e.g. I look forward to studying) and learning related emotions numbering items (e.g. I feel optimistic that I will make good progress in studying) and test-related emotions items (e.g. I have great hope that my abilities will be sufficient). The scale consists of measuring characteristics via point Likert-scale based on rank justification that ranged from 1 strongly disagree - 5 strongly agree. In this study, 15 items used to measure students' emotions with class-related emotions items and learning related emotions numbering items, as well as test-related emotions items (e.g. I have great hope that my abilities will be sufficient). The scale is proven to have good reliability with an alpha coefficient of 0.74 .

\section{Study Results}

The analysis of data was provided by the Statistical Package of Social Science (SPSS). Descriptive statistics were preliminary computed on the study variable. Then the study performed t-test analysis. Table 1 presents the descriptive statistics relative to the study measure both for the total sample and by students' gender. Results of the Leven test across students' gender are also reported. The results of the mean scores of students based on their learning related emotions, test-related emotions which were found to be $(\mathrm{M}=3.107, \mathrm{SD}=.545)$, indicating the above-average score. Moreover, the class-related emotion mean score was found the highest and was above average. Therefore, it can be concluded that Health track students enrolled in the preparatory program at the University of Dammam feel good towards their learning experience.

Table 1: Descriptive Statistics Values for the Learning Related Emotions

\begin{tabular}{lll}
\hline Variable & Mean & SD \\
\hline Total Score & 3.107 & .545 \\
\hline
\end{tabular}

Furthermore, the study employed a t-test to meet the second objective of the research which is to conduct a comparison of the level of learning emotions and its dimensions based on students' gender level. The initial analysis generated insignificant effects on students' gender with the dependent variable. Males and females' groups did not show any differences in their learning emotions. However, the mean score for males' students was $(\mathrm{M}=3.125, \mathrm{SD}=.703)$ and for females $(\mathrm{M}=3.105, \mathrm{SD}=.532)$. Therefore, it can be concluded that significant differences in the average total score of the dependent variable did not exist between the students' gender as shown in Tables 2 and 3 below. 
Table 2: Descriptive Statistics for Male and Female Results

\begin{tabular}{|c|c|c|c|c|}
\hline \multirow{2}{*}{\multicolumn{2}{|c|}{ Male Score Learning Related Emotions }} & Mean & \multicolumn{2}{|l|}{ SD } \\
\hline & & 3.125 & .703 & \\
\hline \multicolumn{2}{|c|}{ Female Score Learning Related Emotions } & 3.105 & .532 & \\
\hline \multicolumn{5}{|c|}{ Table 3: Leven's Test for the Learning Related Emotions } \\
\hline$\overline{\text { Scale }}$ & F-Value & sig & t-value & Sig 2tailed \\
\hline Equal Variance Assumed & 1.606 & .208 & .112 & .911 \\
\hline Equal Variance Not assum & & & .089 & .931 \\
\hline
\end{tabular}

\section{Discussion}

The main aim of the present study was to investigate the different levels of emotions towards learning among students in health track at the university. The present study involved a sample of university students and was aimed at identifying learning related emotions in preparatory year university students, and to compare the learning related emotions between students based on their gender. According to the results, Saudi students generally feel good and positive towards their learning environment. This was expected as data was gathered prior to the final examination period, so students did not experience negative feelings, feelings of anger or feelings of anxiety. This may also be attributed to the fact that many of the students attended counseling sessions during the semester which assisted them in searching for ways to cope with anxiety. However, the counseling sessions normally prepared students for the university environment; forward their challenges to specialists as well as provide them with some reinforcement for their subjects. As for the second objective, the result showed a significant difference between the levels of learning related emotions of students based on their gender. The results found to be insignificant as males and females students have good learning related emotions. However, the result was not surprising since health track students either males or females described to have high classroom support and highly competitive classroom environment. Moreover, the health college offered limited seats for students following their preparatory year at the university. This may have encouraged students to concentrate during their classes and make use of study aids to complete tasks, which will help them recall the information afterword.

\section{Conclusion and Limitations}

The present study is a pioneering study that attempted to assess the students learning emotions towards their learning. In this regard, no study has tested the learning related emotions among health college students. Its strength lies in the inclusion of gender in the analysis that has been ignored in prior studies. As such, the study results have surpassed prior studies in their significance 
to academicians and educators as it evidently provides an insight into student's emotions related to learning, which in this case is above average. Moreover, based on the results, the mean level of emotions related to learning found to be not varied between males and females students.

Beyond its contributions to the studies in the field of education, future research may approach the case under study by using a qualitative method to highlight the actual perception of students of their university success as this study had relied only data from self-report measures. Furthermore, the study concentrates on a single university owing to the limited time appropriated for the subject and hence, future studies could include students from other universities. In conclusion, the results suggest the need for counseling or intervention programs to be developed in consistence with the findings in order to motivate the learning of the students.

\section{References}

Mitsis, A., \& Foley, P. (2012). do generational membership and psychographic characteristics influence positive word of mouth in a university context? Asian Academy of Management Journal, 17(1), 1-12

Zeidner, M. (1998). Test anxiety: the state of the art. New York: Plenum Press.

Pekrun, R., Frenzel, A., \& Thmoas, G. (2007). The control-value theory of achievement emotions: An integrative approached to emotions in education. Emotion in education, pp. 13-36.

Putwain, D., Larkin, D., \& Sander, P. (2013). A reciprocal model of achievement goals and learning related emotions in the first year of undergraduate study. Contemporary Educational Psychology, 38, 361-374.

Harmon-Jones, E., Cindy, H., Amodio, D., \& Glabe, P. (2011). Attitude toward emotions. Journal of Personality and Social Psychology.

Linnenbrink, E. (2007). The role of affect in students learning: A multi-dimensional approach to considering the interaction of affect. Motivation and Engagement. Emotion in Education, pp. 101118. San Diego: Academic Press.

Goetz, T., Frenzel, A., Ludtke, O., \& Hall, N. (2014). Between domain relations of academic emotion: Does having the same instructor make a difference? The Journal of Experimental Education.

Babbie, E. \& Mouton, J. (2010). The practice of social research. Cape Town: Oxford University Press.

Pekrun, R., Goetz, T., \& Perry, R. (2005). Achievement emotions questionnaire user's manual. Munich: The University of Munich. 